\title{
Direitos e deveres relativos à coabitação de pais e filhos maiores e capazes civil e economicamente
}

Francisco de Assis e Silva*

SUMÁRIO: Introdução; 1. Família-sistema jurídico; 2 . Família-conteúdo histórico; 3. Coabitação; Conclusão.

\section{Introdução}

Atraídos, quase sempre, pelas singularidades que um tema escolhido suscita, é difícil não se perceber, de imediato, toda sua relevância, especialmente para neófitos em matéria de Direito de Família. Diz-se, seguindo as orientações de muitos mestres que se aprende admirar, que para interpretar uma lei, urge conhecer todo o Direito, e, mais particularmente, para ensaiar um estudo inaugural sobre um Tema específico do Direito de Família é imprescindível o conhecimento de suas primeiras linhas, seus princípios norteadores e seus deslindes históricos.

Debruçando-se em sua análise, logo depara-se com uma transformação no sistema familiar. Vê-se, acima de tudo, uma vastidão de princípios e direitos, numa zona grísea do direito que carece de uma renovada atenção e interesse ante a necessidade de pesquisa e aperfeiçoamento sobre a família.

Assim é que, nada obstante notar-se um prestigiamento louvável ao direito de Família pelos cultores da ciência jurídica, constata-se, por outro lado, uma soberba desatenção ao que podemos chamar de Direitos e Deveres

* Advogado empresarial; Mestrando do CPGD/UFPR.

R. Fac. Direito. Curitiba, a.27, n.27. 1992/93, p.203-218 
de Coabitação entre Pais e Filhos Maiores e Capazes, assunto para o qual será dirigido este trabalho. Segundo João Uchôa Cavalcanti Netto. ${ }^{1}$

Jogo, o Direito não é a norma nem a rebeldia, mas o conflito abraço de ambas. Ao invés de repelentes, Direito e conflito, inseparáveis, terminam sendo quase um único fenômeno, verso e reverso ${ }^{2}$. Designando a Lei por Direito Positivo, o jurista subentende sem ousar pronunciar, a existência de um direito negativo, a infração, direito também. E é a soma desses direitos antagônicos que estrutura o Direito, um conflito ${ }^{3}$.

\section{Família: sistema jurídico}

Percebe-se, ainda que sob o domínio da ideologia cristã, de que a família surgiu como fundamento da continuidade do homem na face da terra, para que esta fosse inteiramente povoada pela criatura cuja imagem e semelhança era a do Criador. Portanto, o instinto de sobrevivência está ligado necessariamente a reprodução e conservação da espécie assim como o desejo de seu criador. Como ensina Orlando Gomes e Nelson Carneiro ${ }^{4}$ " a continuidade do homem na terra mantém-se através da ininterrupta cadeia de gerações que, sucedendo-se no tempo, conservam a espécie.”

Encontra-se na história, famílias que ao longo de décadas e séculos, mantian-se unidas sem que jamais algum membro ousasse ausentar-se. Quando algum membro ausentava-se da família era por uma espécie de condenação brutal, segundo a qual o filho era banido do seio familiar.

No Direito Romano, encontraremos a figura do paterfamílias que era o único proprietário de todos os bens e os administrava livremente, detendo ainda poderes de vida e morte (vintae ac necis), de venda, de punição de exposição dos recém-nascidos e de reivindicação quando em poder de terceiros. ${ }^{5}$

1 João Uchôa Netto, O Direito um Mito, Rio de Janeiro, Editora Estácio de Sá, 1977, p.

135. Nesta obra, o Autor que é Juiz de Direito traça um paralelo entrea lei positivada e os dógmas impostos pela história do cristianismo, deixando claro sia posição de que a sensação, o pecado (crime) e a lei somente em conjunto podem formar o direito.

2 Idem p. 57.

3 Idem p. 55.

4 Orlando Gomes e Nelson Carneiro, Do Reconhecimento dos filhos adulterinos, Rio de Janeiro, Forense, 1958, p. 15.

5 Silvio A. B. Meira, Instituições de Direito Romano, São Paulo, Max Limonad, 1987, p. 162 . 
Entretanto, qualquer que seja a espécie de família encontrada, os filhos somente deixavam a casa dos pais, expulsos ou casados, para constituição de uma nova família. Do seio da comunidade unida quer pelo afeto, hierarquia, interesses patrimoniais, somente desliga-se aquele membro cuja atitude levará à constituição de uma nova comunidade familiar. Todas as relações jurídicas em torno da família encontram-se centradas no Sistema Jurídico Normativo.

Sem ousar a criação, os Direitos e Deveres de Coabitação Entre Pais e Filhos, irão aparecer como integrantes, também, do mesmo Sistema Jurídico. Para ilustrar essa idéia de sistema, ensina o Professor Juan Manuel Teran, da Universidade do México que Sistema és un conjunto ordenado de elementos segun un punto de vista unitário... Deve entender-se por Sistema Juridico no solo las normas estabelecidas para una comunidad para un País unitariamente, sino tambiém las situaciones jurídicas derivadas de ellas. ${ }^{6}$

Ou seja, o tema proposto não pode ser visto a partir de um ponto isolado e desordenado, mas como parte ou como uma situação jurídica equacionada a todo o sistema jurídico. Ou seja, ainda que vista de forma isolada, essa categoria de Direitos e Deveres deve, necessariamente, ser interpretada do ponto de vista sistemático e inserta no Sistema Jurídico, posto que, se ele protege os laços e relações de famílias, necessariamente o fará para a relação pais e filhos.

Quando se fala em Direitos e Deveres, não se pode ter em mente um conjunto de regras propriamente dito, ordenadas a partir de um sistema lógico, ou seja um conjunto de regras obrigatórias, tendentes a introduzir o homem em um caminho de práticas obrigatórias ou proibidas. O Direito, sim, visto do ponto de vista de Miguel Reale, em sua Filosofia do Direito, quando vislumbra o direito sob três perspectivas dominantes ou seja:

“1) Direito como valor, justo, estudado na filosofia do direito na parte denominada Deontologia Jurídica, ou no plano empírico e pragmático pela Política do Direito:

2) Direito como norma ordenadora da conduta, objeto da ciência do direito ou jurisprudência, e da filosofia do direito no plano epistemológico;

6 Juan Manuel Teran. Filosofia del derecho, Cidade do México. Pavua. 1971. p. 146

R. Fac. Direito. Curitiba, a.27. n.27, 1992/93. p.203-218 
3) Direito como fato social e histórico, objeto da história, da sociologia e da etnologia do Direito; e da filosofia do Direito, na parte da Culturologia Jurídica".

E ainda mais,

A análise fenomenológica da experiência jurídica, confirmada pelos dados históricos suscintamente lembrados, demonstra que a estrutura do Direito é tridimensional, visto como o elemento normativo, que disciplina os comportamentos individuais e coletivos, pressupõe uma dada situação de fato referida a valores determinados. ${ }^{7}$

Torna-se compreensível, a partir desta concepção que os Direitos e Deveres aqui pesquisados, estarão centrados dentro de uma relação jurídica transitória, estabelecida em decorrência da criação de uma entidade familiar.

Em razão dessa relação derivada da família poder-se-á exigir o adimplemento de certas prestações de caráter pessoal-afetivo, vinculada a uma situação de fato, referida a valores de ordem afetiva situados em princípios de solidariedade e equidàde.

Como ensina Vicente Ráo, acerca das Ações Humanas:

"As ações humanas só e unicamente assumem natureza jurídica quando consistem em relações entre pessoas ou se destinam a produzir relações desta natureza, integrando-se no instante em que a bilateralidade pessoal se verifica e conjuga os poderes e deveres que, torna correlativas. Pouco importa que os sujeitos passivos dos deveres jurídico ou obrigações sejam pessoas determinadas, ou indeterminadas, mas determináveis, ou a generalidade de pessoas: menos importa que se trate de obrigação positiva ou negativa. Aquilo que, essencialmente interessa a qualificação das relações de direito e a bilateralidade ou multiplicidade dos poderes e deveres distribuídos entre sujeitos diversos, quer as prestações, ou ações ou modos de comportamento devidos sejam recíprocas, quer não sejam, como ocorre nas relações que uma só das partes obrigam." 8

Portanto, observa-se que há poderes e deveres que gravitam fora da órbita do Direito e poderes e deveres que embora existam dentro dela não se constituem direitos subjetivos.

\footnotetext{
Miguel Reale, Filosofia do Direito, São Paulo, Saraiva, 1986, p. 509-511.

8 Vicente Rao, O Direito e a Vida dos Direitos, São Paulo. Ed. Revista dos Tribunais, 1992, p. 721 .
} 
Aqueles que estão fora são os direitos ligados a ordem espiritual, moral, e os que estão dentro, são os comportamentos da convivência social, que embora não se constituam direitos subjetivos, a ordem Jurídica não os desconhece e sempre os ampara por medidas acautelatórias, até porque são relações entre pessoas que assumem contornos jurídicos, integrando-se ao sistema jurídico, numa necessidade de proteção de tais relações.

O Conceito de direito subjetivo é também apanhado da Obra de Vicente Ráo, segundo o qual

"direito subjetivo é o poder de ação determinado pela vontade que, manifestando-se através das relações entre pessoas, recai sobre atos ou bens materiais e imateriais e é disciplinado e protegido pela ordem jurídica, a fim de assegurar a todos e a cada qual o livre exercício de suas aptidões naturais, em benefício próprio, ou de outrem, ou da comunhão social". ${ }^{9}$

Ter-se-á como lógico e compreensível a adequação das relações entre pais e filhos relativas a coabitação como sendo relações jurídicas que embora gravitem na órbita do direito, não se constitui direito subjetivo, conforme as belas lições de Vicente Ráo.

Segundo o autor citado, algumas relações não se constituem nessa espécie de direito, sem que, entretanto, a ordem jurídica ou os princípios de direito, ou ainda salientado anteriormente, todo o sistema jurídico, não cuidem de proteger tais relações visto que, embora se tratando de comportamento de convivência social, o Direito por ele se interessa, e vem consubstanciando-se no sentido de protege-lo. Nessa ordem de idéias, a família como entidade em todos os seus aspectos, merece a proteção do sistema jurídico em toda a sua amplitude sem fazer distinção entre os períodos cronológicos. Ou seja, não se pode cogitar que a proteção as relações familiares esteja adstrita a uma única fase cronológica, após a qual o direito dela se separa.

Quer analisada do ponto de vista histórico ou normativo, vê-se que a família está jungida a um sistema compreendido em seus princípios fundamentais. De qualquer modo que seja compreendida a coabitação entre Pais e Filhos Maiores, repousar-se-á frontalmente contra o Tema, senão vejamos: em nosso sistema jurídico, haverá sempre a indagação se pode o Pai solicitar ao seu filho, maior, capaz civil e economicamente que saia de

9 Vicente Ráo, O Direito..., op. cit., p. 721.

R. Fac. Direito. Curitiba, a.27, n.27, 1992/93, p.203-218 
sua casa pois não o quer mais morando com ele, ou se do contrário, um filho com as mesmas características querendo sair, poderá ser exigido pelo pai que fique. Este questionamento irá por em discussão princípios jamais concebidos, direitos e garantias individuais asseguradas no texto constitucional, quiçá estaremos novamente partindo para um novo modelo de família.

\section{Família: conteúdo histórico}

Em Roma, encontrava-se a família patriarcal, cuja autoridade máxima competia ao paterfamílias que, como fora aduzido anteriormente, tinha inclusive o poder de vida e morte. O vínculo familiar era voltado para a figura patriarcal, regida pela hierarquia e poder absoluto na mão do paterfamílias, cujo poder somente acabava com a morte. Independentemente da idade, os filhos lhe deviam obediência, independente ainda do seu estado civil.

A Família Germânica, era constituída diferentemente. Havia uma dominação paterna até determinado tempo de vida. Foi na família Germânica, pelo que se tem notícia, que surgiu a idéia de emancipação dos filhos. Quando o filho tinha o que hoje se chama de capacidade econômica, psicológica e legal, distanciava-se do convívio familiar, libertando-se do jugo materno, passando a partir de então ser considerado como pessoa de personalidade própria. O Pátrio Poder entre os Germânicos, não teve a mesma conotação e força como entre os Romanos.

A moderna família aproxima-se muito mais da germânica à Romana. O número de membros torna-se, no entanto, menor. O Pátrio Poder também diminui de extensão, não mais havendo poderes de vida e morte em relação aos membros da família. Inclusive famílias concubinárias ou meras comunidades familiares constituídas de pais e filhos. Ao atingir a adolescência os filhos se libertam, de fato dos Pais.

O Grupo Social reunido em torno do amor, da preservação da espécie e por conseqüência de parentesco, ganha contornos jurídicos e proteção pela ordem jurídica para se adequar ao que aqui chamamos de Sistema Jurídico. Mostra a doutrina, uma tendência pretérita de lhe atribuir uma personalidade jurídica, tendo em vistas certas características peculiares que a le- 
variam a tal qualificação. Ter-se-ia uma pessoa jurídica agindo como uma unidade. Entretanto, a atividade jurídica desse grupo poderá ser exercida, por alguns de seus membros cuja determinação competiria à lei.

Diante da colocação de que as relações atinentes a coabitação entre pais e filhos, embora não se constitua direito subjetivo, é uma relação sobre a qual a Ordem Jurídica deverá deter sua atenção e proteção. Ou seja, caberá ao direito positivo disciplinar o alcance dessas relações, os níveis de proteção jurídica, enfim, normatiza-la. Como dito, pelas definições citadas alhures, não se constitua direito subjetivo, o resultado da convivência harmônica entre pais e filhos maiores e capazes civil e economicamente, interessam ao direito.

A Constituição Federal, em seu artigo 226 impõe: "A família, base da sociedade, tem especial proteção do Estado", arrematando em seu parágrafo oitavo que, o "Estado assegurará a Assistência à Família na pessoa de cada um dos que a integram, criando mecanismos para coibir a violência no âmbito de suas relações". Nesta mesma concepção, o inciso terceiro do artigo quinto estabelece que, "ninguém será submetido a tortura ou a tratamento desumano ou degradante". Portante. constitucionalmente está garantida à entidade familiar, especial proteção do Estado.

Destarte, do ponto de vista do Sistema Jurídico, visto preambularmente a partir da Carta Magna, é vedado à família ou a qualquer um de seus membros, no âmbito de suas relações, qualquer tratamento desumano, degradante ou de violência. Assim, do ponto de vista constitucional, (visto que a atual carta foi é a que mais consolidou garantias a família) as relações familiares merecem a devida atenção do Estado. Está posta uma norma jurídica protegendo e disciplinando relações entre os membros da família sob o prisma de valor, ou seja o valor das relações familiares. E neste ponto, quem protege a família como um todo, certamente o fará sob o ângulo da relação entre Pais e Filhos isoladamente.

Esta especial proteção do Estado eleva a família a um grau importante na esfera de preocupação de todo o sistema jurídico, visto que, ainda analisado perfunctoriamente, considerado como base de toda a estrutura social, esta concepção jurídica cria princípios e direitos subjetivos, cujo decurso do tempo jamais interromperá.

O legislador Constituinte que tudo pode, jamais seria ingênuo em estabelecer uma Norma Constitucional que protegesse a família sem pro-

R. Fac. Direito. Curitiba, a.27. n.27. 1992/93, p.203-218 
teger as relações entre Pais e filhos, vistas do ponto de vista isolado. Como ouve-se dos falares da desembargadora Aura Pimentel Ferreira, com a promulgação da Constituição de 1988, o Estado assumiu o dever de dispensar à família especial proteção, empregar meios necessários, objetivando impedir que a violência e a desarmonia possam estar presentes no âmbito de suas relações. ${ }^{10}$ Ainda que as vicissitudes das relações pessoais, em face da proteção, não degradem a família ou a estilhacem, pondo fim a milenar sociedade de afeto conhecida como família. Salienta a autora citada que "já se disse nessa obra que na família da roma primitiva, os membros do grupo familiar não eram considerados em sua individualidade, perante o estado, já que não tinham personalidade, sendo considerados alieni iuris. ${ }^{11}$

A partir da Constituição, o Estado deve total proteção à família, mediante a edição de leis, que seriam mecanismos tendentes ao fim colimado, para propugnar a relação harmoniosa do grupo familiar, evitando a desintegração ou o fim da família.

Muito embora haja a proteção garantida, como ensina SÁ Pereira "deve, portanto, constituir-se sob um regime de liberdade, que exclua a tirania, e de autoridade, que exclua a anarquia." ${ }^{12}$ Mas, reconhece-se a necessidade de estabelecer regras e mecanismos para por em situação de igualdade não só marido e mulher, filhos legítimos ou não, mas também, de um lado os pais e de outro filhos maiores e capazes civil e economicamente.

Em matéria de família, sobreleva enfatizar, o direito tem cuidado exaustivamente do relacionamento matrimonial, e dos filhos no que tange a legitimidade ou não. Porém, quando o grupo social, reunido em torno do amor/afeto e da preservação da espécie ultrapassa o período de cessação do pátrio poder, não tem merecido especial atenção do direito, dando-se a impressão de ser relações desinteressadas ao Direito, quer para disciplinar ou para coibir excesso, estabelecendo limites.

Não cuidou a lei, nem tão pouco se preocuparam os Cultores da Ciência do Direito se, ao cabo o pátrio poder as relações entre família somente interessam ao direito quando disserem respeito a alimentos, filiação ou ao direito hereditário. Quiçá o direito de família nesta ordem de

10 Áurea Pimentel Ferreira, A nova Constituição e o Direito de Família, São Paulo, Renovar, 1991. p. 86.

11 Idem, p. 15.

12 Citado por Aúrea Pimentel Ferreira, A Nova Consittuição..., op. cit, p. 15. 
idéias contém um antagonismo que afronta a idéia sócio afetiva de família. Ainda mais, talvez, a família após o derradeiro estágio da convivência desaparece como comunidade de afeto, passando seus membros a se relacionar somente de maneira natural, sem que nada seja devido um ao outro, somente como obrigação natural de auto e espontâneo relacionamento.

\section{Coabitação}

Vemos que na grande família patriarcal, o filho, mesmo que casado e ainda seus filhos e os filhos de seus filhos, permanecia no seio familiar, somente dele se desgarrando para constituir uma nova família, um novo clã, poderíamos dizer. O mesmo acontece na família germânica e em geral na moderna. Ao chefe da família (agora marido e mulher segundo a Constituição Federal) cabe o dever de alimentar e educar a prole até que a mesma alcance os patamares da independência econômico afetiva. Essa coabitação fundamenta-se na solidariedade, no afeto e, mesmo na modernidade, constitui-se uma comunidade reunida em torno do amor e do sangue, constituída para à preservação da espécie e até certo ponto de um status social.

O dever de sustento da prole, prolonga-se até a idade determinada pela lei, cessando a obrigação quando cessar o alcance do Pátrio Poder, como ensina o Professor Yussef Said Cahali "sob este aspecto, a orientação mais acertada é aquela no sentido de que, cessada a menoridade, cessa ipso iure a causa jurídica da obrigação de sustento adimplida sob a forma de prestação alimentar, sem que se faça necessário o ajuizamento, pelo devedor, de uma ação exoneratória." 13

Evidentemente a obrigação jurídica de alimentar a prole englobará inclusive uma moradia, que, em casos específicos não significará a mesma, basta vermos os casos de pais separados. Entretanto, para o estudo do tema deve-se olvidar a questão alimentar, para não causar confusão de que a coabitação estará necessariamente ligada a questão alimentar ou de qualquer outro tipo de dependência entre pais e filhos. Não estará o filho coabitando com os pais por mera necessidade financeira ou psicológica mas sim, porque há uma comunidade familiar que coabita induzida pelo afeto e relações entre si que derivam da sua própria essência.

13 Yussef Said Cahali, Dos Alimentos. São Paulo, Ed. Revista dos Tribunais. 1986. p. 440.

R. Fac. Direito. Curitiba. a.27. n.27. 1992/93. p.203-218 
Alcançada a maioridade, cessará o Pátrio Poder. Porém, cessando também, junto com o Pátrio Poder a obrigação alimentar, e, estando os filhos sob o mesmo teto, cessará também essa relação a coabitação dos respectivos filhos, também assegurados como Direitos e Garantias Individuais na Constituição Federal?

Pode-se indagar, a partir desta análise, distanciada agora da questão alimentar, que estamos diante de uma lacuna da lei, vez que não haverá resposta à pergunta formulada, nem mesmo à questão anteriormente posta, se o Pai, quando o filho completar 21 anos, ou mais, poderá exigir que 0 mesmo retire-se, buscando para si outro lar e outro domicílio. Ainda mais, se o filho ao atingir a maioridade poderá querer tomar citada atitude sem que o Pai possa se opor. Não parece clara a conclusão positiva ou negativa, visto que, como analisado anteriormente, embora não se configure direitos subjetivos que emergem dessa relação familiar, são relações que merecem e requerem a proteção de todo o Sistema Jurídico Normativo.

O Professor Francisco José Ferrreira Muniz, na companhia de José Lamartine Correa de Oliveira proclama que a obrigação de sustento se prolonga além da maioridade quando o filho não tenha terminado seus estudos. ${ }^{14}$ Aparentemente é uma das poucas passagens doutrinárias que trata das relações entre Pais e Filhos maiores, porém, ainda sob o ponto de vista alimentar.

Para Rosseau, citado por Eduardo Oliveira Leite, ${ }^{15}$ a família somente se mantém ligada enquanto os filhos precisam dos pais, e quando essa necessidade se esvai, cada qual, isentos da obediência recobrem-se de igualdade e independência. Pais e filhos tornam-se iguais e independentes, cada qual tendo a responsabilidade consigo mesmo. Ou seja, não há um desapego aos laços naturais e biológicos, mas há um rompimento dos laços de responsabilidades jurídicas entre pais e filhos. Rompendo-se a hierarquia familiar, ninguém obedece ninguém. Contesta Rosseau, segundo Eduardo Oliveira Leite, a possibilidade da mantença de qualquer vínculo familiar a partir desta independência, voltando-se a espontaneidade e afeto para que essa característica passe a ser a razão da existência dessa mesma família.

14 Francisco José Ferreira Muniz e Iosé Lamartine Correa de Oliveira, Direito de Família, Direito matrimonial, Porto Alegre. Sérgio Fabris. 1990. p. 24.

15 Eduardo de Oliveira Leite. Tratado Direito de Família, vol. I: "Origem e Evolução do Casamento". Curitiba, Juruá, 1994, p. 341. 
Sendo o cidadão livre para contratar, o é também para ter ou não relações com a comunidade familiar que o levou à maioridade e independência. A obrigação do pai estaria em fazer da criança que nasceu livre, porém frágil, um ser forte e independente sem a necessidade de estar sob a hierarquia e autoridade de seus progenitores. para Rosseau, ${ }^{16}$ "cada família torna-se mais unida na medida em que o apego recíproco e a liberdade constituem seus únicos laços, a família deixa de ser uma sociedade natural e evolui tornando-se uma sociedade voluntária, exclusivamente fundada no amor e na liberdade".

Muitas vezes essa obrigação de educar o filho e levá-lo, quando da maioridade a uma independência para a qual foi nascido, era exercida por outras pessoas, sendo os filhos mantidos a distância das próprias famílias, ainda que tradicionais, como ensina Eduardo Oliveira Leite.

De qualquer forma, a relação familiar de coabitação entre pais e filhos, esta necessariamente condenada a extinguir-se com a maioridade, sem que, entretanto, tenha-se mecanismos jurídicos e legais para circundar a questão de uma forma mais objetiva.

Entrevistando pessoas das mais variadas classes sociais, e mesmo vários advogados militantes na área de Família, percebe-se que em relação ao tema há uma consideração quase que unânime, ou seja a de que os pais devem educar os filhos, posto que ao gerá-los obrigaram-se a certas prestações, sendo que a principal é, na maioridade entregá-los capazes e independentes à sociedade, sob pena de continuar na obrigação de sustento. Mesmo assim, essa obrigação tem o condão de fazer do filho um ser livre e independente, inclusive da família. Ou seja, não haveria a partir de então, qualquer obrigação de coabitação, sendo que esse relacionamento manifestado por cada qual dos membros, sendo absolutamente possível que o pai abrisse mão da convivência do filho em seu lar, sem possibilidade jurídicoprocessual de impedí-lo de deixar a mesma casa, quando o ato partisse da deliberação do próprio filho. Não haveria assim, direitos ou deveres de coabitação entre pais e filhos maiores e capazes. Porém, é unânime a idéia de lacuna acerca do tema.

16 Eduardo de Oliveira Leite. Tratado..., op. cit, p. 341.

17 Idem, p. 542. 543. 544.

R. Fac. Direito, Curitiba, a.27. n.27. 1992/93. p.203-218 
Nada obstante essa noção, há que se indagar se quando a Constituição Federal assegurou proteção à família contra qualquer tratamento desumano ou degradante, não deixou claro, ainda que inversamente interpretado, haver tratamentos desumanos e degradantes?

Não seria forçoso concluir que, muito embora cessada a obrigação alimentar, impedir que o filho consigo continue morando é um tratamento desumano e degradante, posto que na prática o que se pretende na verdade é expulsar o filho de casa, posto que já se tornou um estorvo e a Comunidade de Afeto até então apregoada e buscada não mais existe. Como diz Vicente Ráo ${ }^{18}$ a multiplicidade de casos ocorrentes e das circunstâncias particulares que os cercam, exerce a capacidade de previsão da legislação e sua possibilidade de incluí-los sem omissões ou defeitos, nas fórmulas gerais em que a lei se concretiza.

Essa ausência de previsibilidade na lei somente será solucionada se se permitir ao Juiz, num caso concreto como o atacado pelo tema lançar mão da eqüidade, para suprir a dissonância entre a previsão legal e o fato concreto. Vê-se que aplicadas as três regras fundamentais da eqüidade vislumbrar-se-á uma luz para a solução do tema.

a) por igual devem ser tratadas as coisas e desigualmente as desiguais - pais e filhos maiores e capazes civil e economicamente devem ser tratados de forma igual;

b) todos os elementos que concorram para constituir a relação subjudice, coisa ou pessoa ou que, no tocante a estas tenham importâncias, ou sobre elas exerçam influência, devem ser devidamente consideradas - a comunidade familiar como valor, alicerçada no afeto deve ser considerada;

c) entre várias soluções possíveis deve-se preferir a mais suave e humana, por ser a que melhor atende o sentido de piedade, e de benevolência - o tratamento desumano ou degradante deve ser levado em conta, e, uma vez já havendo proteção constitucional a solução do caso concreto deve atender ao sentido mais suave e mais humano.

A própria função da eqüidade, entre várias, é de realizar, no caso da omissão da Lei, um tratamento de benignidade e de humanidade. Assim, bisando o posicionamento anterior de que as relações de família (no tema

18 Eduardo de Oliveira Leite, Tratado..., op. cit, p. 65. 
analisado) são relações sociais que não se constituem direitos subjetivos, porém o sistema jurídico necessariamente se preocupará em solucionar sempre que houver conflito de interesses, deverá fazê-lo em obediência ao princípio da eqüidade.

De par com o tema e a busca de sua solução deve-se ainda ser levado em conta o Direito a Intimidade, também assegurado em nossa Carta Magna, que hoje apresenta aspectos circunscritos a esfera jurídica. A vida privada de uma forma geral invadida por uma série de transformações tecnológicas não pode, em nome de uma Comunidade Familiar ser considerada em planos secundários, mesmo porque fugir-se-ia da própria aplicação da eqüidade.

Edoardo Gianotti, em trabalho acerca da Tutela Constitucional da Intimidade, tece vários comentários acerca da proibição da inviolabilidade do domicílio e da vida privada de cada indivíduo, até colocando intimidade e vida privada no mesmo ponto de consideração, asseverando que o Direito a intimidade faz parte da natureza humana e dos direitos imprescritíveis do homem. ${ }^{19}$ Nesta mesma linha de respeitabilidade à intimidade, estaria a inviolabilidade do domicílio visto que "o domicílio é independente da noção de propriedade, mais ligado ao respeito à personalidade. A proteção é garantida, não importando a que título é ocupada a casa; locatário, usufrutário ou mesmo proprietário". ${ }^{20}$ A violação do domicílio como violação ao direito de intimidade é a violação da própria liberdade pessoal. "O Direito que todo o indivíduo possui de atuar livremente dentro do espaço físico que lhe é reservado, para realização de sua vida privada, sem que seja perturbado pela presença não autorizada de outras pessoas. ${ }^{21}$

A intimidade caracteriza-se por pressupostos pessoais e espaciais ou ambientais que visam assegurar ao homem todas as formas de manifestação de sua personalidade, direito este amplamente assegurado pela Constituição de 1988, consagrado pela doutrina e jurisprudência, impondo responsabilidade civil e criminal a quem atentar contra a Intimidade. A intimidade dos pais estaria amplamente garantida perante a Carta Maior, quando em seu louvor, desautorizasse o filho que consigo morasse a partir de cumpridas as

\footnotetext{
19 Eduardo Gianotti, A Tutela Constitucional da Intimidade, Rio de Janeiro, Forense, 1987, p. 47

20 Idem, p. 91.

21 Idem, p. 16.
}

R. Fac. Direito. Curitiba, a.27. n.27. 1992/93.p.203-218 
obrigações que se comprometeram no momento da geração do filho e no estabelecimento de uma comunidade familiar.

Porém, bisando posicionamento anterior, esse mesmo direito à intimidade deve ser observado na análise do tema, posto que, como se viu, o domicílio é inviolável independentemente de que título é ocupada a casa, visto que está mais ligado à noção de personalidade e não de propriedade. Diante dessa dicotomia é que a eqüidade poderá aparecer como equilíbrio de direito, ou ainda como equilíbrio nas relações sociais entre Pais e Filhos, maiores e capazes civil e economicamente. Não se trata de um equilíbrio de forças mas, sim, um equilíbrio para que o Poder Judiciário, ao apreciar a questão, decida de acordo com a aplicação do princípio de eqüidade, para que diante de todas as soluções possíveis, prevaleça a mais harmonioso e mais humana, para não discrepar do mandamento Constitucional que veda tratamentos desumanos e degradantes, que por certo vedará também decisões desumanas e degradantes.

Não se poderá fugir da necessidade de se palmilhar um caminho na busca de um entendimento razoável. O Juiz não pode se abster de proferir uma decisão ao caso concreto se concluir, da mesma forma, que há uma lacuna. Deverá fazê-lo em obediência ao artigo $4^{\circ}$ da Lei de Introdução ao Código Civil, à Luz dos Princípios de Direitos de Família constitucionalmente Garantidos e em louvor a Eqüidade.

\section{Conclusão}

O Professor Francisco José Ferreira Muniz ${ }^{22}$ apregoa que há de se constituir o que chama de Direito Judicial dos Princípios Constitucionais do Direito de Família, uma vez que as garantias constitucionais e seus princípios terão o condão de inaugurar a já esperada Reforma no Direito de Família. Essas reformas poderão aquilatar também soluções a casos concretos como o presente tema escolhido, através das manifestações da Jurisprudência. Ou seja, diante da Lacuna, a matéria ressentindo de uma legislação específica, fatalmente a jurisprudência se antecipará à Lei, visto que há um fato social cuja atenção do direito é exigida.

22 Francisco José Ferreira Muniz, Congresso Brasileiro de Magistratura Belo Horizonte 14 e 16 de novembro de 1.991, Belo Horizonte, 1991, p. 20. 
Não há que se falar em comportamento jurisprudencial acerca do tema posto que não há previsão de julgados nessa direção. O Tema posto torna-se um desafio para que os Legisladores e os Juristas da área de Família dediquem algumas pesquisas, debruçando-se sobre uma constante preocupação de não se findar a família, quer no ponto de vista social ou jurídico, quando a maioridade for alcançada. A família não pode simplesmente acabar quando cessar certos períodos cronológicos.

A família tem vivido momentos onde se questiona sua própria existência, quando seu fim foi por muitos comemorado na expectativa de que, diante de dificuldades jurídicas, legais, psicológicas e sociais a comunidade familiar tivesse efetivamente acabado. Entretanto não se pode fugir da idéia de que a família evoluiu, os critérios e leis absurdas aos poucos vão desaparecendo e uma comunidade reunida em torno do amor e da afetividade cada vez mais se consolida e solidifica raízes afetivas. Como de forma iluminada resumiu Michelle Perrot

"Não é a família em si que nossos contemporâneos recusam, mas o modelo
excessivamente rígido e normativo que assumiu no século XIX. Eles rejei-
tavam o nó, não o ninho. A casa é, cada vez mais, o centro da existência. O
lar oferece, num mundo duro, um abrigo, uma proteção, um pouco de calor
humano. O que eles desejam é conciliar as vantagens da solidariedade
familiar e as da liberdade individual. Tateando, esboçam novos modelos de
família, mais igualitária nas relações de sexo e de idades, mais flexíveis em
suas temporalidades e em seus componentes, menos sujeitas às regras e mais
ao desejo. O que se gostaria de conservar na família são seus aspectos
positivos: a solidariedade, a fraternidade a ajuda mútua, os laços de afeto e
amor. Belo Sonho!" 23

Não há melhor expressão sobre a forma de comportamento que deve ter a doutrina, a lei e a jurisprudência, senão essa, expressada por Michelle Perrot, em defesa do ninho como meio de afeto e de amor e em repúdio ao nó que impede as relações de solidariedade, de fraternidade e de ajuda mútua.

23 Michele Perrot, "O Nó e o Ninho", Veja, São Paulo, abril de 1993, p. 81.

R. Fac. Direito, Curitiba, a.27, n.27. 1992/93, p.203-218 


\section{Referências Bibliográficas}

AARÃO REIS, Carlos David S. Família e Igualdade. $1^{\text {a }}$ edição. São Paulo: Renovar, 1991, $142 p$.

ALMADA, Ney de Mello. Direitos de Familia. $1^{\text {a }}$ edição. São Paulo: Brasiliense, 1986, 350p.

BEVILÁQUA, Clóvis. Direito de Familia. $1^{a}$ edição. Rio de Janeiro: Freitas Bastos. 1943, $437 \mathrm{p}$.

BÍBLIA SAGRADA, 32a . edição. Rio de Janeiro: Imprensa Bíblica Brasileira, 1991, 1.188p.

CAHALI, Iussef Said. Dos Alimentos. $1^{\text {a }}$ edição. São Paulo: Ed. Revista dos Ttribunais, 1986, $697 \mathrm{p}$.

CAPRA, Fritijof. O Ponto de Mutação. $1^{a}$ edição. São Paulo: Cultrix, 1982, 447p.

CAVALCANTI Neto, João Uchôa. O Direito um Mito. $2^{\text {a }}$ edição. Rio de Janeiro: Estácio de Sá, 1990, 135p.

GOMES, Orlando. Direito de família. $2^{\mathrm{a}}$ edição. Rio de Janeiro: Forense, 1958, 447p.

GOMES, Orlando; CARNEIRO, Nelson. O Reconhecimento dos Filhos Adulterinos. $2^{\mathrm{a}}$ edição. Rio de Janeiro: Forense, 1958, 423p.

MEIRA, Silvio A. B. Instituições de Direito Romano. $4^{a}$ edição. Edição Max Limonad, 1987, 380p.

MELLO, Baptista de. Direitos de Bastarda. $1^{a}$ edição. São Paulo: Saraiva, 1993, 481p.

MELLO, Celso Antonio Bandeira de. O conteúdo Jurídico do Principio de Igualdade. $1^{\text {a }}$ edição. São Paulo: Ed. Revista dos Tribunais, 1978, 60p.

RÁO, Vicente. O Direito e a Vida dos Direitos, $3^{\mathrm{a}}$ edição. São Paulo: Ed. Revista dos Tribunais, 1992, 908p.

TERAN, Juan Manuel. Filosofia Del Derecho, $5^{\text {a }}$ edição. Cidade do México: Pavua, 1971, 470p. 